Review

\title{
A Comprehensive Review on Internet of Things (IoT) and its Implications in the Mining Industry
}

\author{
${ }^{1}$ Fatemeh Molaei, ${ }^{2 *}$ Elham Rahimi, ${ }^{1}$ Hossein Siavoshi, ${ }^{3}$ Setareh Ghaychi Afrouz and ${ }^{1}$ Victor Tenorio \\ ${ }^{I}$ Department of Mining and Geological Engineering, University of Arizona, Tucson, USA \\ ${ }^{2}$ Department of Mineral Engineering, New Mexico Institute of Mining and Technology, Socorro, USA \\ ${ }^{3}$ Department of Mining and Minerals Engineering, Virginia Polytechnic Institute and State University, Blacksburg, USA
}

\author{
Article history \\ Received: 26-07-2020 \\ Revised: 19-08-2020 \\ Accepted: 03-09-2020 \\ Corresponding Author \\ Elham Rahimi \\ Department of Mineral \\ Engineering, New Mexico \\ Institute of Mining and \\ Technology, Socorro, USA \\ Email: elham.rahimi@student.nmt.edu
}

\begin{abstract}
The integration of computer-based technologies interacting with industrial machines or home appliances through an interconnected network, for teleoperation, workflow control, switching to autonomous mode, or collecting data automatically using a variety of sensors, is known as Internet of Things (IoT). When applied inside an industrial context, it is possible to immediately benefit from the analytics obtained, contributing to process optimization, machine health, the safety of workers and asset management. IoT can assist real-time platforms in remotely monitoring and operating a complex production system with minimal intervention of humans. Hence it can be beneficial for hazardous industries, such as mining, by increasing the safety of personnel and equipment while reducing operation costs. An ideal smart automated mine could potentially be achievable by gradually taking advantage of IoT. Currently, different sensors are used in mine-related activities, such as geophones in exploration and blast control, piezometers in dewatering and toxic gas detectors in working frontlines. However, a fully integrated automated system is challenging in practice due to infrastructural limitations in communication, data management and storage. Moreover, the tendency of mining companies to continue with traditional methods instead of relying on untested novel techniques decelerates this progress. In this study, the adaptability of the mining industry to IoT systems and its current development is reviewed. Significant challenges of this progress are investigated and recommendations to develop a comprehensive model suited for different mining sections such as exploration, operation and safety considering flexible technologies such as Wireless Sensor Networks and the introduction of Global Data Management.
\end{abstract}

Keywords: Internet of Things (IoT), Smart Mining, Wireless Sensor Networks (WSNS), Automation, Database Management

\section{Introduction}

Mining is the most fundamental industry in the supply chain of resources for manufacturing, technology development and construction. Modern life depends on the exploration and extraction of minerals, such as metals, non-metals, aggregates, coal and strategic elements like REEs (Rahimi et al., 2016; Shekarian et al., 2017). The population growth exacerbates the demand for resource extraction (Futurist, 2001). Even coal remains the primary source of energy up to 2050 (Cliff et al., 2019;
National Academies of Sciences, Engineering and Medicine, 2018). The mineral extraction, however, is challenging due to the uncertainty in ore reserve estimation, unknown nature of in situ rock, supplying energy for the operation, commodity price volatility, dangerous working conditions for health and safety of miners and environmental concerns (Rahimi et al., 2016; Fairhurst, 2017; Carvalho, 2017; Saxena, 2017). Recent advances in technology have been facilitated the mining industry to overcome these challenges with remote sensing, three-dimensional ore reserve simulation, remote automated 
machinery, highly efficient excavators and real-time data monitoring (Saxena, 2017; National Research Council, 1992; Sabins, 1999; Humphreys, 2001).

Innovative techniques in data processing and remote controlling are evolving all stages of mining from exploration to consumption patterns (Asgari et al., 2019; Rahimi et al., 2020). Artificial Intelligence (AI) is a reliable tool for data analysis and decision making in case of dealing with large or repeating sets of data (Russell and Norvig, 2002). Other than robotic applications, AI is used for pattern recognition using Machine Learning (ML) and user interaction using apps or smart devices. AI rapid development focused on overcoming human physical limitations by studying the potential telepathic communication between people, inventing prosthetic eyes with $\mathrm{Wi}-\mathrm{Fi}$ and so on. Similarly, mining companies are investing in applying ML algorithms on old school methods to develop a smarter mine, for example, in geological survey data and optimizing the drilling targets (Saroufim, 2016; CSIRO Futures, 2017; Mahmoodpour et al., 2018; Watt and Eng, 2018).

Besides, robotics has been significantly advantageous in mines by replacing labor in dangerous tasks such as underground excavating or deep-sea mining (Chakravorty, 2019). While humans are safe being away from hazardous working conditions, trained operators and technicians are still required to keep the robots always functioning and engineers to design the machines and plan the operations. Automation in mining is developing rapidly and industrial programmable computers or Primary Logic Controllers (PLC) are smaller and more compatible with numerous communication ports. Moreover, sensors have become more advanced in recent years. Virtually all features of a task can be measured, monitored and evaluated quantitatively. The data obtained can be used to optimize operations, improve the quality of performance and increase the safety of operations. Likewise, in the mining activity, all tasks at any stage of production can be measured and monitored, the data adequately collected and stored, communicated and analyzed to take maximum benefit of it. The Internet of Things (IoT) is the infrastructure that can ease this process (Fig. 1). Correspondingly, the need for experts in programming, communication maintenance and process control is increasing in this new working panorama (Kibira et al., 2016; Shahmoradi et al., 2020a).

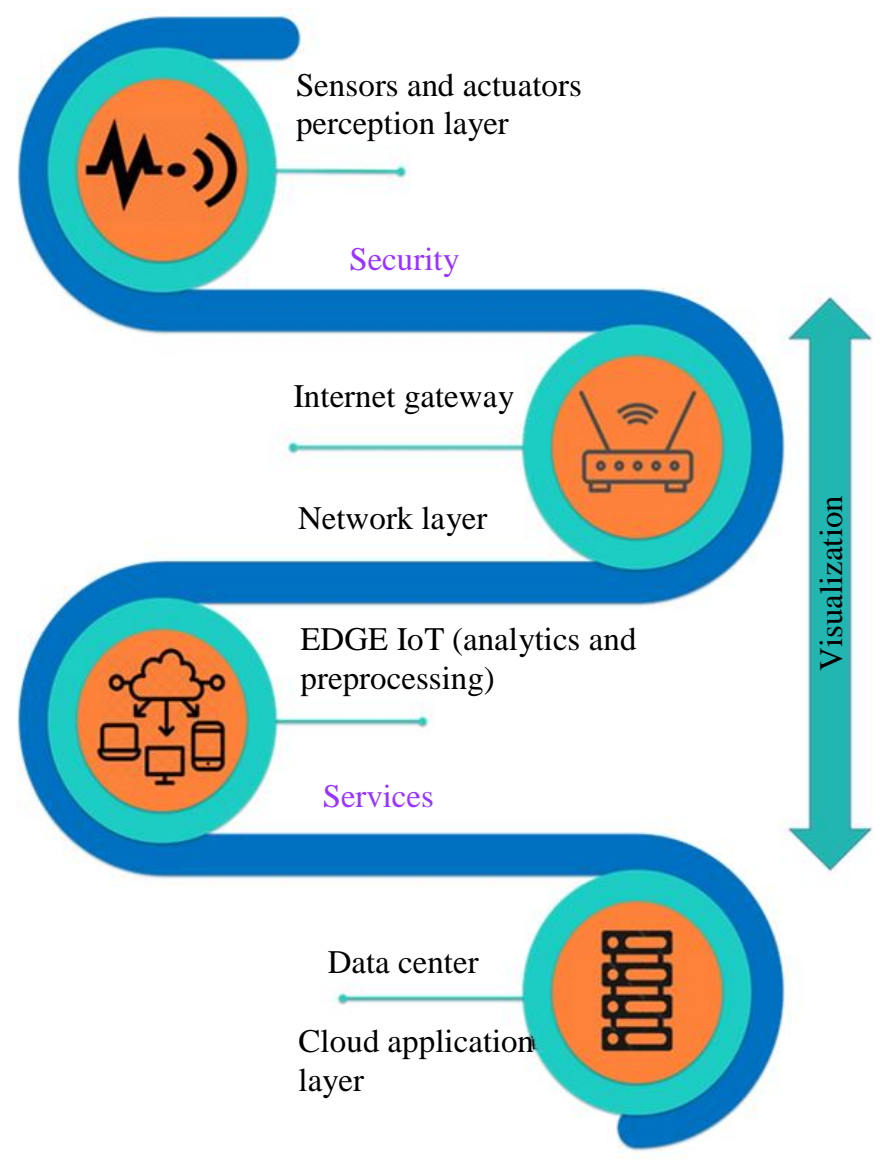

Fig. 1: The Schematic architecture of IoT 
Applications of sensors, robotics and machine learning have been increased in mining industry and technology is changing all stages of mining from exploration to reclamation. IoT development in mines; however, has some challenges due to limited infrastructures such as sufficient network coverage, extensive data transfer and data storage systems (Fig. 1). Also, automation and smart devices is updating mining daily practices such as health and safety procedures in drill and blast (Khomenko et al., 2011). Mine engineers have to review the applicability of these novel methods and educate operating crews accordingly. Several studies introduced and discussed a specific modern technique using recent technologies such as AI and its challenges at a particular stage of mining (Ghasemi et al., 2014; Muduli et al., 2018; Ghaychi Afrouz and Westman, 2018; Chakravorty, 2019; Hyder et al., 2019; McGaughey, 2020). Few studies also specifically introduced IoT for a single task in mining such tailing dam monitoring (Sun et al., 2012), coal mine monitoring system (Hu et al., 2013; Bo et al., 2014; Zhou et al., 2017), positioning systems in coal mines (Liu et al., 2010; Liu and Liu, 2014), ventilation and gas monitoring (Qin et al., 2011; Qian et al., 2016; Gillies et al., 2004; Jo and Khan, 2018), roof support (Singh et al., 2018), maintenance and machinery safety (Atkins et al., 2010; Zhang et al., 2014; McNinch et al., 2019). Hyder et al. (2019) investigated the application of modern techniques in automation of mining industry; nevertheless, the challenges of applications of IoT are not evaluated in the literature. This study has a unique perspective on reviewing the general application of IoT in different stages of mining considering its challenges and probable feasible solutions.

\section{Internet of Things (IoT)}

IoT is a mixture of integrated technologies, including connected sensors, receivers, actuator devices and internet-related physical items, which can communicate via a network to achieve common objectives (Pallavi and Sarangi, 2017). Its origin refers to the application of Radio-Frequency Identification (RFID) in tracking objects, back in 1999 (Greer et al., 2019). IoT requires network infrastructure with several linked devices; hence, its development depends on sensory technology, communication, networking and data processing. There is no limit for the size of an IoT-based system and it can be installed on a global network with many devices (Khan et al., 2012; Pallavi and Sarangi, 2017). Good examples of this are several mobile phone and computer applications that have been recently developed based on data received from one or more sensors connected to the Internet (Wortmann and Flüchter, 2015).
Discover how IoT can help manufacturers optimizes equipment for better performance and why a global cloud platform provides a foundation for success. To businesses the advantages of IoT depend on their individual application; agility and performance are typically top priorities. Manufacturers add sensors to their product components so they can retransmit data on how they work.

IoT use can be categorized into two segments: Industry-specific services such as sensors in a real-time healthcare devices (Woo et al., 2018), building blocks (Kumar and Mallick, 2018; Mijić and Varga, 2018; Almeida et al., 2019a), smart tracking (Song et al., 2019; Anandhi et al., 2019), smart manufacturing (Ezell 2016; Yang et al., 2019) and IoT products that can be used in all sectors, such as smart environment (Jaykumar and Blessy 2014; Arridha et al., 2017; Souri et al., 2019) smart energy (Fensel et al., 2017; Vishwakarma et al., 2019; Sittón-Candanedo et al., 2019; Nižetić et al., 2019) risk management (Hiromoto et al., 2017; Malik and Singh, 2019; Radanliev et al., 2019), security (Naik and Maral, 2017; Khan and Salah, 2018) and IoT analytics (Markkanen, 2015; Patel et al., 2017; Banerjee et al., 2018).

The large amounts of data produced by IoT devices require extreme performance for interacting and communicating with each other. IoT in cloud provides the connectivity needed to share information between devices and make sense of it at a rapid pace. The IoT storage system allows to monitor key information on objects when traveling across cloud platforms. The provision of accurately knowledge of current IoT data processing, which results in greater accessibility and a flexible supply of resources, is a significant value for IoT applications (Cai et al. 2016; Amin et al., 2018; Alam and Benaida, 2019).

Since prehistoric times, mining has been able to change and IoT is at the forefront of this transformation (Khan et al., 2012; Dong et al., 2017). The intense work and potentially dangerous mining activities appeal to smart devices and advanced connectivity and communication undeniable (Pallavi and Sarangi, 2017). There is an increasing interest in different sectors using IoT technologies. Figure 2 illustrates the required elements of IoT and application of IoT in different areas.

In an industry such as mining in which efficiency and productivity improvements are essential to profitability, even small enhancement in travel-time of the equipment can impact the efficiency of the operation tremendously (Yinghua et al., 2012; Zhou et al., 2017). Mining companies produce interchangeable products in the primary and mining leaders are increasingly looking at advanced technologies as they prepare for the future of businesses to turn challenges into opportunities. The potentials of using IoT in different sections of the mining industry are illustrated in Table 1 . 

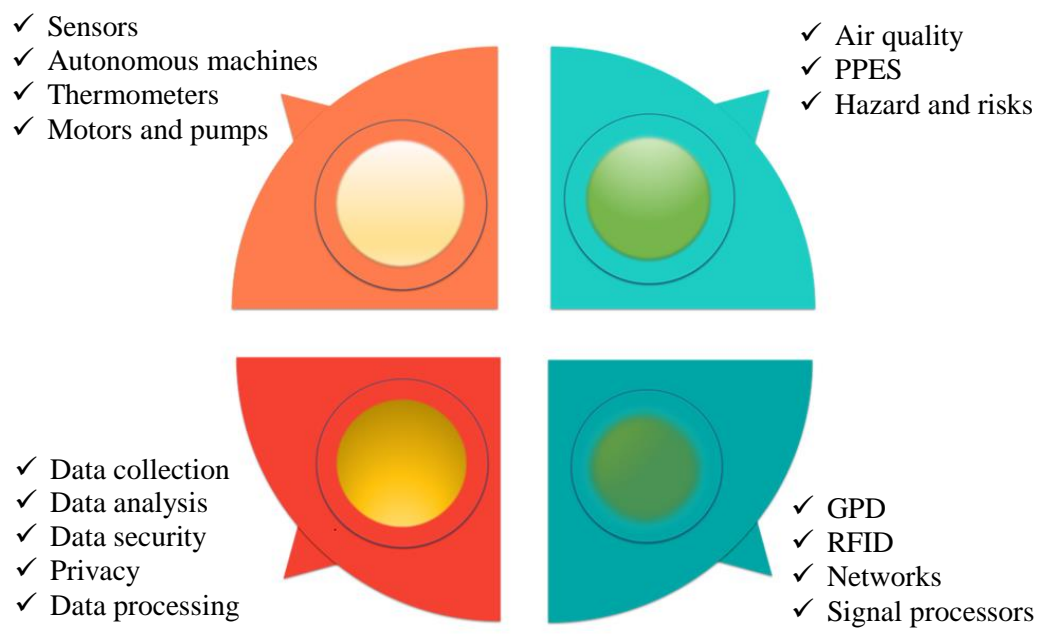

Fig. 2: Utilization of IoT devices for mining and other industrial applications. IoT collect data using sensors, communicate it through network to data collection bases for engineered analysis. The results will be visualized for decision making

Table 1: Literature related to IoT in the mining industry

\begin{tabular}{|c|c|c|}
\hline IoT Application & Output & Reference \\
\hline Coal Mine gas wireless monitoring system based on WSNs & Monitoring System & Qin et al. (2011) \\
\hline Coal mining employee positioning system & System & Liu et al. (2010) \\
\hline Tailings Dam monitoring and pre-alarm system in mines & TDMPAS System & Sun et al. (2012) \\
\hline Tracking of equipment for maintenance in the Mining Industry & Database & Atkins et al. (2010) \\
\hline Reliability evaluation of Coal Mines using Internet of Things & Model & Kunkun and Xiangong (2014) \\
\hline Monitoring System for Coal Mines & System Architecture & Bo et al. (2014) \\
\hline Iron Ore Concentration Plant & Optimization & Saroufim (2016) \\
\hline Sensing, Monitoring and Prediction of Underground Mines Roof Support & Model & Singh et al. (2018) \\
\hline Improve Machine Safety & System & McNinch et al. (2019) \\
\hline Underground Coal Mines & Feasibility Study & Zhou et al. (2017) \\
\hline Accident Analysis and Big Data in Coal Mines & System & Xia et al. (2018) \\
\hline Coal Mine Safety Supervision & Supervising System & Zhang et al. (2014) \\
\hline Design of Detection System for Mine Oxygen Concentration & System Design & Qian et al. (2016) \\
\hline Coal Mine Monitoring System & Monitoring System & Hu et al. 2013) \\
\hline Realization of Real-Time Location System in Coal Mines & System & Liu and Liu (2014) \\
\hline Fleet and Personnel Management & Managing Plan & Dessureault (2019) \\
\hline Ventilation Monitoring & Real-time Monitoring System & Gillies et al. (2004) \\
\hline Underground Mine Air Quality Pollutant Prediction & System & Jo and Khan (2018) \\
\hline
\end{tabular}

A comprehensive review of the application of IoT in different areas of mining has been accomplished. To better understand the story, this paper presents four main categories to implement a system based on IoT as follows; Wireless Sensor Networks (WSNs), Data Management, Automation and Applications in the Mining Industry (Fig. 3).

\section{Data Transfer and Communication}

Communication is critical in the mining industry, as it affects both production and safety. It is necessary for the transfer of data between personnel and data collection from machinery. The way of communication in underground and surface mines is changing rapidly. For example, radio once was the primary communicating device within both types of mining, although today, smartphones are more common, especially in surface mines. The history of communication in mines goes back to person-to-person carrying information, which then was updated to wire transfer by advances in telecommunication (Paavola and Seppälä, 2016; Forooshani et al., 2013). A wireless network connection is challenging due to the limited coverage and signal shortage in mines.

Earlier communication in underground mines was based on wired phones, which with the help of carrier current transceivers on mine locomotives, the range of the coverage was extended (Murphy and Parkinson, 1978). Later, electromagnetic wave propagation through Earth made radio communication possible; however, it is limited to the ultra-low frequency with a low penetration rate in rocks, which causes inadequate signal coverage and high noise. Additionally, the infrastructure requires extra support during mining activities such as blasting (Murphy and Parkinson, 1978; Carreño et al., 2016). Wireless radios and phones were the main tools to transfer information in and out underground sites. Still, a 
more efficient solution with a larger capacity of data transfer rate was needed (Chironis, 1976).

\section{Wireless and Sensor Networks (WSNS)}

The Wireless Sensor Networks (WSNS) was an evolution in communication and monitoring underground areas, which helped to achieve a safer mining production (Chehri et al., 2009; Bhattacharjee et al., 2012). They provide the connection between surface and some predefined sensor base points as nodes in underground spaces. Bluetooth (BT), WLAN and ZigBee can be applied for data transfer through WSNs (Paavola and Seppälä, 2016). These technologies are different in distance range, data rate, power consumption and maintenance required.

WSNs require hardware and software design that can be architecture, within a network to have the most efficient data transmission, called network topology (Callaway et al., 2002). In a case study by (Wang et al., 2009), the coal mine production was monitored through a robustly designed WSN, including data acquiring sensors such as for methane gas and temperature. The data acquisition is filtered and calibrated in the system and then distributed to the end-users through several devices, such as antennas, radios and computers.

The number of communication nodes, the distance and the speed of data transmission are critical in WSN systems. Some of the negative aspects of this network that could be mentioned are that they are known as highpower consumption nodes, cluster access points for storage, continuous power and cable access points. Therefore, there is no multi-hop network topology between Wi-Fi nodes, but data between nodes and access points can be transferred. The ZigBee network is a simpler, more reliable WSN device that is widely used for overcoming shortcomings of other underground WSNs, such as Bluetooth and Wi-Fi. The characteristics of various WSNs for underground communication and data transfer are shown in Table 2 (Moridi et al., 2014).

ZigBee has optimal distances between nodes, is energy-efficient, has a more straightforward network installation and requires lower maintenance. Moreover, this network works with a lower data rate (about 250 $\mathrm{kbps}$ ). ZigBee was recently used for a variety of applications in the field of mine safety, mainly for underground coal mines, as automatic meter readers and remote control systems, with the aid of other WSNs (Hongjiang and Shuangyou, 2008; Chehri et al., 2011; Moridi et al., 2014; Dessureault, 2019).

\section{Global Positioning System and Coordination}

Determining the three-dimensional location of checkpoints, geochemical sampling, geological structures and mineralization zones are precisely required in all stages of mining from exploration to reclamation (Shekarian et al., 2017; Battulwar et al., 2020). Finding the location of the geological structures orebodies and opening underground, however, is a different challenge in the mining and even oil and gas industry (Asgari et al., 2019; Rahimi et al., 2019). The Global Positioning System (GPS) is used in open pit mining for surveying with high accuracy of $2 \mathrm{~cm}$ horizontally and $3 \mathrm{~cm}$ vertically (National Research Council, 1992). Moreover, it improves productivity and operations safety by its applications in grading, machinery guidance, drilling, dozing, slope stability monitoring, microseismic monitoring and fleet management (Yagimli and Varol, 2009; Nieto and Dagdelen, 2003; Ghaychi Afrouz, 2020). GPS defines location and time information of any point on the surface of the Earth based on satellite navigation with clear line sight of at least four satellites. The distance of each location to satellites is calculated from the speed of light and travel time of the sent and received signals (Kaplan and Hegarty, 2005). The Real-Time Kinematic Global Positioning System (RTK-GPS) is a precise method with which the changes in the coordinates of each point can be tracked (Satalich and Ricketson, 1998).

The coordinates of sensors and equipment are the necessary information about any object targeted for data acquisition in mines. Most data analysis is dependent on the coordinates of the points that are continually changing. In underground mines, however, the coordinates of the points cannot be found with GPS navigation due to a limited range of signal transmission below the surface and lack of satellite coverage in depth. Hence, surveying is obtained traditionally by the theodolite and regional positioning coordinate systems. RTK-GPS can be combined with Close-Range Photogrammetry (CRP) and total stations in underground mines. CRP is the technique to define the coordinates of the points of digital images in a local coordinate system on pictures.

Table 2: Comparison between WSN technologies modified after (Moridi et al., 2014)

\begin{tabular}{lllll}
\hline Parameters & Bluetooth & UWB & Wi-Fi & ZigBee \\
\hline Communication distance $(\mathrm{m})$ & 10 & $<10$ & $50-100$ & $50-500$ \\
Frequency range (GHz) & 2.4 & $3.1-10.6$ & 2.4 or 5 & 2.4 \\
Data rate (Mbps) & 1 & $100-500$ & 11 & $250 \times 10^{-3}$ \\
Network Capacity (nodes) & 7 & $10-500$ & 32 & 65,536 \\
Power consumption (mW) & $1-100$ & 30 & $500-1000$ & $20-40$ \\
Complexity & High & Medium-High & High & Low \\
\hline
\end{tabular}


Moreover, recently RFID systems were helpful in zoning danger areas and alarming the dispatch center, while drone technologies adapted for operating in narrow and confined spaces such as mine excavations are used for gas monitoring, point-cloud scanning, surveillance and visual reconnaissance of inaccessible areas, among other applications (Shahmoradi et al., 2020b).

\section{Data Management in the Mining Industry}

One of the main study topics for the next few years could be how to store more data than the human population information generated by objects. It is necessary to use mechanisms and frameworks to collect, store and handle information produced in IoT procedures to meet this challenge in IoT apps (Fan and Chen, 2010; Abbasi et al., 2017; Bohli et al., 2015). Organizations need to modernize in several key areas, including the adoption of new technologies and systems for data management, as well as the creation of new policies for data governance.

Several studies are investigating how to store, represent and validate the information to guarantee maximum effectiveness and non-repudiation in its retrieval and updating. To maximize sharing, the objects will need to be self-descriptive and can report on dynamic features. The availability of IoT Systems is essential to accommodate consistent and ongoing data generation operation (Abbasi et al., 2017).

In today's global marketplace, mining businesses are facing progressively complicated leadership difficulties. One of the most challenges is to produce smart, actionable information about operating outcomes, properties and reserves when the supporting data is spread through geographically distributed apps. Traditional approaches to the use of mining data systems cannot provide the right people with the right information in the correct form and at the right time. Global access is an increasing need for users across wide geographic limits that require coherent information action in their indigenous languages. Several internal powers, though, are now exerting pressure on mining companies to use this data more effectively. On the other hand, mining firms have identified that control of the workflow, data-driven planning and decision making are critical and of real value for their sustainability. Using the best digital technology, including Cloud Mobility, Big Data analytics and the IoT, provide mining companies to connect the Mining Value Chain from the sensors to the Board Management (I-SCOOP, 2017).

Within a single software application, a Database Management System stores, organizes, modifies and manages huge information that allows users to connect to a database efficiently and keeps information organized and available. A core function of the data management system is to provide consistent data sets of known quality to end-users. Data management systems also provide a better framework for data privacy enforcement and safety regulations. Moreover, a data management system promotes a comprehensive picture of the operations of an organization and helps to see how processes affect other sectors in one part of it. Consequently, a higher quality database helps in better and faster decision making in the company (Watt and Eng, 2018).

The different devices commonly enter and leave the system and produce large amounts of information in the IoT platform. This information, particularly for the variety of sensor systems, maybe disordered or discontinuous. To tackle the problem that manages the data produced by these systems, there is a viable technique that encapsulates device functions as services and data management as sub-services for application utilization (Abbasi et al., 2017; Fan and Chen, 2010).

There are three primary and critical benefits for the mining industry by using a standard database to create a central repository of information for the systems throughout a mining operation: First, establishing one version of the "truth" and eliminating inconsistency among the systems. Second, providing inherent data integrity and security. A central database also guarantees the security of sensitive mine data because it is possible to establish, implement and disclose standardized backup practices to managers. Third, a centralized database is universally accessible, reducing unnecessary delays in accessing information, usually when people need to manually request and share information and enable processing and manipulation of data independent of their sources (Moignard, 2008).

\section{Challenges and Benefits of IoT and Technology Application}

The mining sector is already going through a revolution in automation. Digitization will be at the forefront of the industry investment in the future. The competitive advantage will eventually be gained by companies that harness and invest in instruments to analyze their information. Digitization may not necessarily be new to the mining sector, but the industry is struggling to find a way to make the most of it. Recent activities of exploration and mining produce large quantities of data. At all stages of the life of the mining cycle, having a timely authenticated, relevant and visual data is critical. Some of the data management problems have been eased by continuous improvements in computing capacity and technology, but a gap continues (Knight, 2018). For example, as mentioned before, advanced operations in the mining cycle produce large amounts of field data. While software packages for data analysis have made significant progress in interpretation and visualization, they can be expensive and complicated, requiring the intervention of expert technicians. It remains an elusive target for effective, productive and accurate management of the mining data (Fan and Chen, 2010; Abbasi et al., 2017). 
Table 3: Challenges and benefits of IoT application

$\begin{array}{ll}\begin{array}{l}\text { Challenges in data storage and management (Abbasi et al., 2017; } \\ \text { Barrie } \text { et al., 2017; Harbers et al., 2018; Elijah } \text { et al., 2018) }\end{array} & \begin{array}{l}\text { Top benefits of IoT in Mining (Zhang et al., 2014; Dlamini and } \\ \text { Johnston, 2016; Frustaci } \text { et al., 2017; Harbers et al., 2018) }\end{array} \\ \text { - Data integrity } & \end{array}$

Data once studied and analyzed, produces information. Working with data on IoT needs a shorter time compared to raw data gathered from people and later transformed into information. Moreover, the introduction of technology continually changes the nature of the operator's task. Perhaps supplementary technology can solve the original problem but brings other issues, not the least of which is more massive complexity and less predictability by human operators. For example, the main meltdown of the Three Mile Island (TMI) occurred in part because operators were confused about what was going on. This was moderately due to the difficulty in the operation of the plant and suggests that the workers were unable to handle the specific and voluminous data from conventional alarms, indicators and control devices during emergency conditions (Lynas and Horberry, 2011). Table 3 shows the challenges and benefits of IoT application.

\section{Progressive Automation in Mining}

Automation is generally defined as intelligent systems management using appropriate technology to perform without the direct participation of human beings (Sheridan and Parasuraman, 2005). Progress in mining automation has been commenced during the 1960s. In 1967, the first underground railcars were produced in General Blumenthal Mine (Germany), which was developed in Europe and the U.S. during the 1970s The U.S. was also developed at this time with automated drills. In the mid1970 s, underground remote-control mining systems were introduced in this second automation phase. Two cameras provided superficial tracking of these systems via operators. The third phase occurred in the mid-1990s when some coal-fired technologies were changed for hard rock mines. They used their load and haul machines, or "boggers" remotely controlled from the surface. Automatic shotcreting and rock-bolting machines have also been remotely operated but they still have to be operated by humans (Lynas and Horberry, 2011).

Automation is generally considered more productive, reliable and precise than a human operator. The automatic control system will, therefore, perform a task with lower costs than the operator, which is sometimes wrong. Operators are needed when an unexpected event occurs, such as during maintenance/failure or when the system designer is unable to automate any aspect of the systems (Horberry et al., 2016). System-based automation and new technologies in mining are classified into three broad categories:

- Lower level automation, including warning systems such as detection and signaling technology for maintenance of equipment. The operator is always in full control of the system in this context and the technology provides an alert and assistance

- Mid-level automation which could involve either replacing the operator control from a nearby location or making the operator control the equipment at certain times. Examples include the use of material when the operator is a passive controller who acts when it is considered necessary. In this classification, the operator is mainly responsible for equipment, but some functions are automatically controlled and monitored by the operator

- Full automation with the operators' remote location and the use of a computer monitor, joysticks, or other controllers and the display (Endsley, 1999) found that the operator was less aware of the situation than was observed at the intermediate level 
under full automation. Additional studies have shown that intermediate automation is preferable to retain controller awareness at a higher level and to allow critical functions to be performed (Endsley and Kiris, 1995; Endsley, 1999). The dynamic allocation of system control functions to the human operator and/or computer over time results in adaptive automation to optimize system performance. Controller awareness should be preserved by allowing a better combination of task requirements and cognitive resources (Visser et al., 2008; Kaber et al., 2001). This supports previous (Kaber and Riley, 1999), which argues that, under such a system, operator awareness and readiness for unforeseen system conditions should be increased

While the competition between mining companies is increasing, many of them are investigating new techniques to improve the efficiency and protection of a mine site. As far as the findings of a survey are concerned, most of the mining companies believe that IoT is an effective way of achieving these objectives. This research showed that $70 \%$ of the respondents in 100 large mining companies believe that IoT would provide them a major advantage compared with competitors. Mining operators also addressed how IoT would contribute to boosting their competitiveness: $41 \%$ said they would use IoT to increase the efficiency of their business processes and $44 \%$ said that it would help them identify cost savings and growth opportunities (Mining Technology, 2019).

\section{Application of IoT in the Mining Industry}

Presently, it is possible to look across all different areas in a mine with IoT and people can identify patterns from seemingly unrelated variables (Yinghua et al., 2012; Khan et al., 2012; Sun et al., 2012; Dong et al., 2017; Behr et al., 2016; Zhou et al., 2017). The Internet of Things is speeding up the pace of feedback by delivering ultra-short-term interval controls, which means that people can look at things as they are happening and not after the fact (Atkins et al., 2010; Liu et al., 2013; Xu et al., 2014; Thomas and Rad, 2018). This means that mine executives can optimize not only a certain aspect but also the whole mining value chain (Saroufim, 2016; Sharma et al., 2017a; Singh et al., 2018).

\section{Predictable Mining Operation}

Mining is going to become more predictable through the Internet of Things and Big Data advanced analytics (Saroufim, 2016; Sharma et al., 2017a; Dong et al., 2017; Singh et al., 2018). A considerable number of generated information expected to be able to make decisions efficiently (Sun et al., 2012; Singh et al., 2018; Rahimi et al., 2020). This process requires cognitive computing to create automated mine planning (Sun et al., 2012; Mahdavinejad et al., 2018). Moreover, linking the mine operation to macroeconomic and microeconomic data would result in the mine responding automatically to the fluctuations in demand (Dong et al., 2017). A significant change using the IoT was recently achieved by (Saroufim, 2016) in one of the big iron mining companies in South America. In this concentration plant, a massive number of data has been produced, monitored and collected. On the other hand, the required time for regular analysis of all the data-driven will indeed cause a rise in costs of the mine. In this mine, an automated predictive-maintenance system was created, using IoT and Machine Learning, which can predict the quality of the Concentrator Plant output and improve it automatically through variable model adjustment. The high quality of iron products with a meager amount of impurities in a reduced operational cost and shorter timeframe would indicate the benefits of IoT in a processing plant (Saroufim, 2016).

The predictability of potential risks in the mining industry is achieved by IoT that imply various sensors and real-time monitoring (Sun et al., 2012). Tailings dam failures all around the World, caused irreparable losses, which, for the most occurred in developing countries (Almeida et al., 2019a; Lyu et al., 2019). A recent example that illustrates the importance of this is the Brumadinho Dam disaster, a tailings dam of iron ore mine in Brazil, which occurred in January 2019 and left behind a considerable number of fatalities, with damages on the environment and the local economy (Almeida et al., 2019b). According to the usual reasons for dam failures, (Sun et al., 2012) presented a significant model for Tailings Dam Monitoring and Pre-Alarm System (TDMPAS) based on IoT and Cloud Computing (CC). This simply defined framework consists of three layers of sensors, networks and applications. Therefore, sensors continually measure pressure, water level, rainfall and deformation, which within embedded GPSs, the exact location of the deficiencies in the tailings dam could be identified.

\section{Mining Safety Increases}

IoT, as an emerging network technology based on the convergence of wireless technologies, Microelectromechanical Systems (MEMS) and the Internet, could transform the mining sector by generating new methods of keeping mine safety and productivity (Qiuping et al., 2011). The features of general data perception, secure information transmission and smart information processing have accomplished the purpose of intelligent control and management (Tomar et al., 2018); IoT features offer an 
efficient assurance that the development of mining safety is prior awareness and precautionary progress made to avoid major accidents (Singh et al., 2018).

A large amount of IoT implementation research on mine safety manufacturing was currently conducted in all nations (Yinghua et al., 2012; Sharma et al., 2017b; Dong et al., 2017). Mining is going to change to become safer since technology is enabling mining to occur remotely (Chehri et al., 2011; Hongjiang and Shuangyou, 2008; Moridi et al., 2014). People can sit in the comfort of an office environment and use drones, automated robotic systems, or remotely controlled equipment to perform the mining operations (Bo et al., 2014; Moridi et al., 2014; Qiuping et al., 2011; Singh et al., 2018; Battulwar et al., 2020). Monitoring of environmental parameters in realtime, such as temperature, humidity, pressure, presence of certain gases, water, electricity, etc. and analyzes alerts can be configured for average or instant values of these parameters (National Academies of Sciences, Engineering and Medicine, 2018; Drews et al., 2020). Production of coal, as the most common underground mining operation, is associated with the distribution of dust particles, emission of strata gases and methane concentration, etc. in the working area (Cliff et al., 2019). A coal mine in China is implementing the premature notification and prediction of various disasters and incidents that can be achieved by detecting mine disasters (Qiuping et al., 2011). The features of general data perception, secure information transmission and smart information processing have accomplished the purpose of intelligent control and management (Dong et al., 2017; Parasher et al., 2019).

IoT can help prevent the collapse of unstable shafts for example, because the sensors will pick up realtime data and predict the faulty equipment or where issues may occur, which allows for adjustments to be made before anything goes wrong (Dong et al., 2017; Singh et al., 2018). A notable study by (Singh et al., 2018) presented a model for roof support in underground coal mines known as Self-Advancing Goaf Edge Support Systems (SAGES). By applying IoT, this mobile support system has been fostered for depillaring operation technologies.

\section{Surveillance Systems in Underground Mining}

The development of the IoT has made massive changes, as foreseen in the Fourth Industrial Revolution, especially in industries, such as mining (Qiuping et al., 2011; Sharma et al., 2017a). This progressive technology enables underground mine surveillance more efficiently and effortlessly (Chen et al., 2014). Through adopting the IoT technology, tracking of personnel working in subsurface areas is provided by informational devices used for accurate locations in underground mines
(Yinghua et al., 2012). Early alerting of severe disasters provides an essential step towards secure mine operations that could prevent mortal catastrophes or severe diseases during the time. Based on IoT technology, different kinds of nanotechnology detectors can be mounted on major sites by indicating vibration, temperature, density and other essential details (Sharma et al., 2017a; Behr et al., 2016). Monitors check the abnormalities and problems, then send the collected data to the data processing devices (Khan et al., 2012; Singh et al., 2018). For instance, once a blast has been performed to open a new site inside the mine, the area must be cleared of toxic gases, dust and debris (Yinghua et al., 2012; Behr et al., 2016). In the absence of a controlled air system, miners must wait hours before restarting work to make sure that re-entering is safe (Sun et al., 2012; Dong et al., 2017). Through the incorporation of an aerial management scheme, mine managers, shift supervisors and miners are prepared to understand immediately if the pit is secure (Zhou et al., 2017).

Mine production alongside environmental hazards, such as an explosion, toxic gases, dust, water, roof support, etc. in different complicated operating circumstances restrict underground mining (Lebedev, 2016; Peik, 2020). The complex and hazardous characteristics of the subsurface mining environment have raised the demand for IoT technologies to analyze for more safety in mines (Xu et al., 2014). An example of a safe mine in the underground is active RFID-based wireless for occupational safety and traceability of the mining areas, which is an integrated solution that comprises of tag sensors and readers for tracking people, collecting environmental data, vehicle tracking and real-time alerts (Atkins et al., 2010; Liu et al., 2013; Thomas and Rad, 2018). RFID transmitter devices are mounted on headlamps belts or badge cards of miners to enable tracking of workers in real-time (Yinghua et al., 2012; Chen et al., 2014). When a worker enters the mine, the software automatically enrolls the worker by maintaining a count. This tracking of people works both horizontally within deep mine tunnels and vertically across mine elevators, no cellular network or Internet required with the help of the smart software solution (Atkins et al., 2010; Xu et al., 2014; Thomas and Rad, 2018). The virtual zones can be defined in mines for safe access by workers; therefore, accurate location is always monitored and made available (Qiuping et al., 2011; Liu et al., 2013). The system can provide the location of who are nearby forbidden zones, which are defined as unsafe zones that a worker should never enter (Thomas and Rad, 2018). When a worker enters a forbidden zone, his or her RFID transmitter will start buzzing automatically (Qiuping et al., 2011; Xu et al., 2014). 


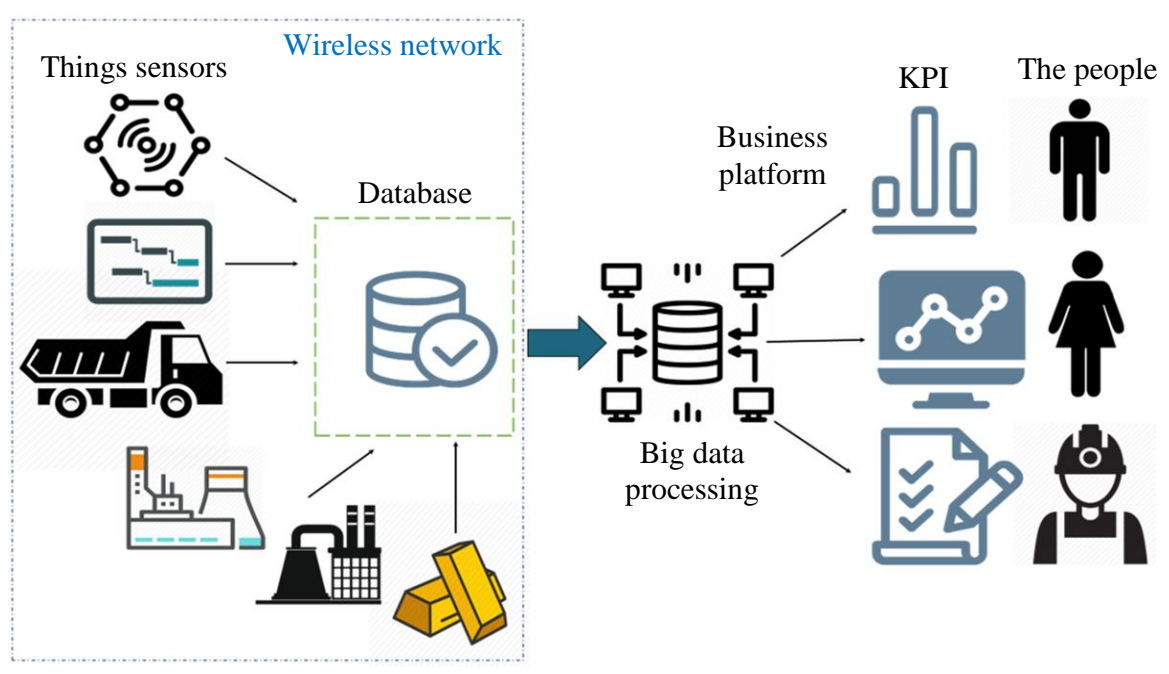

Fig. 3: Schematic view of IoT components in the mining industry

\section{Optimization by Efficient Data Representation}

An IoT platform allows consistent in-real-time data visualization to help quickly address problems while tracking the scale of changes in the closed-loop performance metrics (Fig. 3). This enables IoT solutions to minimize production loss and increases efficiency to understand better the broader impacts on the mining industry of IoT and Big Data. First of all, IoT solutions will incorporate additional data analysis and visualization for the next optimization stage to the remote activity of mine sites and plants. Secondly, when the mining process is integrated across the value chain, the downstream process uploads in real-time data. (Saroufim, 2016).

Nowadays, some mining companies strive to use Machine Learning to make ore finding more of a science than an art. They are working together to use artificial intelligence to review all available geological information to find better ore drilling sites in the World. These endeavors become more accurate when using Machine Learning to find new areas to mine, thus helping the mining industry to be more profitable. Also, mining companies are already using autonomous loaders and drilling systems for several years. Just as with other stand-alone applications, the companies assert the innovation has improved productivity away much higher (Battulwar et al., 2020).

Data from different mining stages are stored in a database through a wireless network. This stored data is processed by required algorithms and the output is reported in graph or table formats to managers, engineers and field operators.

\section{Discussion}

By forging real-time connections between people, machinery, environmental conditions and business processes, the Internet of Things has the potential to transform many industries. In that sense, the Internet of Things can be seen as an opportunity to change the mining industry in day-to-day activities exponentially. However, it can be a challenge to implement comprehensive IoT solutions and even more complicated when underground operations are carried out. Interestingly, mining - one of the heavy industries where the ability to monitor workers and manage equipment remotely can have the most significant impact, is a case where the usual suspects in IoT communication run into a real barrier. Nonetheless, some mining operations have started to collaborate with technology firms to develop creative solutions by installing underground wireless networks. The tracking of workers and equipment helps to create a better working environment, enhance safety, improve maintenance and increase efficiency.

Mines are becoming highly monitored working sites, with remote sensors capable of controlling everything from gas levels to ground stability. Such sensors are continually receiving input and sending this data to applications that can track and alert hazard operators. Remote-controlled and autonomous vehicles are increasingly becoming the norm, capable of being visualized in 3D space and positioned around objects without human intervention. Maintenance schemes will become predictive, with more live monitoring of equipment to detect partial failures before they occur. Nonetheless, mining companies could unblock advantages beyond mining automation by permitting IoT to enhance existing technologies or welcome new IT products and services.

Despite the advances in digital sensors and Big Data processing to making simple activities automated and smart with minimum human intervention, the mining industry still has many challenges to connect equipment 
and operations in each stage of mining, store and analyze data and share the results.

Mining operators must focus on safety and excellence, business pillars that cannot be negotiated in the production costs. IoT is the approach to follow for each of them. To unfold the potential of process improvement across the entire value chain, IoT must become central to mining companies. Industries can look at items off the shelf instead of personalized cost-saving approaches. But a small step can sometimes change the future of an organization.

Capital investment in IoT reduces the energy expenditure and maintenance costs of mining companies. The transparency of a system that monitors all components makes a much more efficient process possible. As this tends to increase, workers' costs will gradually be reduced, making the industry more profitable. Monitoring every aspect of the production process in a holistic mode is much easier than building an interconnected network that leads only to higher productivity and increased safety. Machine Health is another critical component required in the system. It involves wear and tears detection of vital parts of equipment when maintenance or repairs are needed. More data is harvested, which can improve accuracy rates by using stand-alone products, such as vehicles and equipment. IoT allows mining companies to keep up to date with cutting edge innovations, technology and trends in development. It also impacts the perspective of management when new information is available and more effective decisions can be made. In combination, the result is a seamless experience that facilitates the overall job.

Bullet points of challenges for the application of IoT are summarized as:

- Changing the current mining practices and techniques

- Optimizing efficiency

- Smart Mines and Artificial Intelligence

- Blockchain and the Mining Sector

- Drone technology for increasing mine safety

- Training the operators and technicians

- Preserving authenticity in the gold supply chain

- Technology for Underground Operations

- How to overcome deficiencies of IoT with application in automation and connect main mining operations with automation

\section{Conclusion}

Currently mines are using IoT for specific tasks in various stages of mining such as gas detection, positioning equipment, locating personnel and real-time tailing dam monitoring. However; there is no integrated infrastructure with which all data could be recorded and stored in an organized database. In this way data can be processed by assigned professionals and the results will be available in an easy-to-interpret format such as graphs or tables for use of managers and in-filed employees. The essential challenges to achieve this goal are providing a high-coverage network, high-capacity data storage, a user-friendly data management platform and training operation crews.

The result is that mines can be safer for workers, more cost-effective and efficient to operate using Internet of Things (IoT). However, a future in which all mines are completely intelligent is still far away. This future requires an infrastructure to overcome challenges of installation of applications in Mining. A proper communicating network and database management system to transfer and store information are significance of these challenges. Current WSN and digital clouds have shown a great potential for this application. To recapitulate, there are some gaps and consequently promising opportunities to use IoT in the mining industry. For instance, using IoT to make energy consumption more efficient, making a smart environment in the mine sites, optimizing risk management and mitigation plans, using cloud computing to retain data, smart manufacturing and etc. are some of the plausible utilization of IoT in the mining industry.

\section{Acknowledgment}

The author, Fatemeh Molaei, wishes to express her thanks for the financial support of Freeport McMoRan Inc. in her education. The authors sincerely appreciate all valuable comments and suggestions provided by the reviewers of the journal, which helped to improve the quality of the paper.

\section{Author's Contributions}

Fatemeh Molaei: Conceived of the presented idea and developed the Data Management section. Contributed to idea development, database preparation and writing the manuscript.

Elham Rahimi: Supervised the project and provided a database for research studies, also, developed the Application of IoT in the Mining industry section. contributed to idea development, database preparation and writing the manuscript.

Hossein Siavoshi: Developed Progressive Automation in the Mining industry section. Contributed to idea development, database preparation and writing the manuscript.

Setareh Ghaychi Afrouz: Developed Data Transfer and Communication section. Contributed to idea development, database preparation and writing the manuscript. 
Victor Tenorio: Helped to approve the writing and finalized the final manuscript. Contributed to idea development, database preparation and writing the manuscript.

All authors discussed the results and contributed to the final manuscript.

\section{Ethics}

This article is original and contains unpublished material. The corresponding author confirms that all of the other authors have read and approved the manuscript and no ethical issues involved.

\section{References}

Abbasi, M. A., Memon, Z. A., Memon, J., Syed, T. Q., \& Alshboul, R. (2017). Addressing the future data management challenges in iot: A proposed framework. International Journal of Advanced Computer Science and Applications, 8(5), 197-207.

Alam, T., \& Benaida, M. (2019). The role of cloudMANET framework in the internet of things (IoT). arXiv preprint arXiv:1902.09436.

Almeida, I. M. D., Jackson Filho, J. M., \& Vilela, R. A. D. G. (2019a). Reasons for investigating the organizational dynamics of the Vale tailings dam disaster in Brumadinho, Minas Gerais State, Brazil. Cadernos de saude publica, 35(4).

Almeida, T. D., Avalone, M. C., \& Fettermann, D. C. (2019b). Building blocks for the development of an IoT business model. Journal of Strategy and Management.

Amin, R., Kumar, N., Biswas, G. P., Iqbal, R., \& Chang, V. (2018). A light weight authentication protocol for IoT-enabled devices in distributed Cloud Computing environment. Future Generation Computer Systems, 78, 1005-1019.

Anandhi, S., Anitha, R., \& Sureshkumar, V. (2019). IoT enabled RFID authentication and secure object tracking system for smart logistics. Wireless Personal Communications, 104(2), 543-560.

Arridha, R., Sukaridhoto, S., Pramadihanto, D., \& Funabiki, N. (2017). Classification extension based on IoT-big data analytic for smart environment monitoring and analytic in real-time system. International Journal of Space-Based and Situated Computing, 7(2), 82-93.

Asgari, G. R., Ghaemi, F., Soleimany, B., Rahimi, B., \& Shekarian, Y. (2019). Role of incompetent strata and geometry of faults on the folding mechanism, a case study: the Karun oil field in the Dezful Embayment, Iran. Modeling Earth Systems and Environment, 5(4), 1781-1800.
Atkins, A., Zhang, L., \& Yu, H. (2010). Application of RFID and Mobile technology in Tracking of Equipment for Maintenance in the Mining Industry. In The Australasian Institute of Mining and Metallurgy (pp. 350-358). University of Wollongong.

Banerjee, S., Chattopadhyay, T., Pal, A., \& Garain, U. (2018). Automation of feature engineering for iot analytics. ACM SIGBED Review, 15(2), 24-30.

Barrie, G., Whyte, A., \& Bell, J. (2017, March). IoT security: challenges and solutions for mining. In Proceedings of the Second International Conference on Internet of things, Data and Cloud Computing (pp. 1-9).

Battulwar, R., Winkelmaier, G., Valencia, J., Naghadehi, M. Z., Peik, B., Abbasi, B., ... \& Sattarvand, J. (2020). A Practical Methodology for Generating High-Resolution 3D Models of Open-Pit Slopes Using UAVs: Flight Path Planning and Optimization. Remote Sensing, 12(14), 2283.

Behr, C. J., Kumar, A., \& Hancke, G. P. (2016, March). A smart helmet for air quality and hazardous event detection for the mining industry. In 2016 IEEE International Conference on Industrial Technology (ICIT) (pp. 2026-2031). IEEE.

Bhattacharjee, S., Roy, P., Ghosh, S., Misra, S., \& Obaidat, M. S. (2012). Wireless sensor networkbased fire detection, alarming, monitoring and prevention system for Bord-and-Pillar coal mines. Journal of Systems and Software, 85(3), 571-581.

Bo, C., Xin, C., Zhongyi, Z., Chengwen, Z., \& Junliang, C. (2014). Web of things-based remote monitoring system for coal mine safety using wireless sensor network. International Journal of Distributed Sensor Networks, 10(8), 323127.

Bohli, J. M., Skarmeta, A., Moreno, M. V., García, D., \& Langendörfer, P. (2015, April). SMARTIE project: Secure IoT data management for smart cities. In 2015 International Conference on Recent Advances in Internet of Things (RIoT) (pp. 1-6). IEEE.

Cai, H., Xu, B., Jiang, L., \& Vasilakos, A. V. (2016). IoT-based big data storage systems in cloud computing: perspectives and challenges. IEEE Internet of Things Journal, 4(1), 75-87.

Callaway, E., Gorday, P., Hester, L., Gutierrez, J. A., Naeve, M., Heile, B., \& Bahl, V. (2002). Home networking with IEEE 802.15. 4: a developing standard for low-rate wireless personal area networks. IEEE Communications magazine, 40(8), 70-77.

Carreño, J., Silva, L., Neves, S., Aguayo, L., Braga, A. J., Barreto, A. N., \& Garcia, L. U. (2016). ThroughThe-Earth (TTE) Communications for Underground Mines. Journal of Communication and Information Systems, 31(1). 
Carvalho, F. P. (2017). Mining industry and sustainable development: time for change. Food Energy Secur 6 (2): 61-77.

Chakravorty, A. (2019). Underground Robots: How Robotics Is Changing the Mining Industry. https://eos.org/features/underground-robots-howrobotics-is-changing-the-mining-industry

Chehri, A., Farjow, W., Mouftah, H. T., \& Fernando, X. (2011, May). Design of wireless sensor network for mine safety monitoring. In 2011 24th Canadian Conference on Electrical and Computer Engineering (CCECE) (pp. 001532-001535). IEEE.

Chehri, A., Fortier, P., \& Tardif, P. M. (2009). UWBbased sensor networks for localization in mining environments. Ad Hoc Networks, 7(5), 987-1000.

Chen, C. M., Chen, S. M., Zheng, X., Chen, P. Y., \& Sun, H. M. (2014). A secure RFID authentication protocol adopting error correction code. The Scientific World Journal, 2014.

Chironis, N. P. (1976). Super communication system designed to enhance control of operations at Robena Mine. Coal Age;(United States), 81(6).

Cliff, D., LaBranche, N., Shepherd, M., \& Djukic, F. (2019). Improving Respirable Coal Dust Exposure Monitoring and Control.

CSIRO Futures. (2017). Mining equipment, technology and services: a roadmap for unlocking future growth opportunities for Australia.

Dessureault, S. (2019). Rethinking Fleet and Personnel Management in the Era of IoT, Big Data, Gamification and Low-Cost Tablet Technology. Mining, Metallurgy \& Exploration, 36(4), 591-596.

Dlamini, N. N., \& Johnston, K. (2016, November). The use, benefits and challenges of using the Internet of Things (IoT) in retail businesses: A literature review. In 2016 International Conference on Advances in Computing and Communication Engineering (ICACCE) (pp. 430-436). IEEE.

Dong, L., Mingyue, R., \& Guoying, M. (2017). Application of internet of things technology on predictive maintenance system of coal equipment. Procedia engineering, 174, 885-889.

Drews, F. A., Rogers, W. P., Talebi, E., \& Lee, S. (2020). The Experience and Management of Fatigue: A Study of Mine Haulage Operators. Mining, Metallurgy \& Exploration, 1-10.

Elijah, O., Rahman, T. A., Orikumhi, I., Leow, C. Y., \& Hindia, M. N. (2018). An overview of Internet of Things (IoT) and data analytics in agriculture: Benefits and challenges. IEEE Internet of Things Journal, 5(5), 3758-3773.

Endsley, M. R. (1999). Level of automation effects on performance, situation awareness and workload in a dynamic control task. Ergonomics, 42(3), 462-492.
Endsley, M. R., \& Kiris, E. O. (1995). The out-of-theloop performance problem and level of control in automation. Human factors, 37(2), 381-394.

Ezell, S. (2016). IoT and smart manufacturing. Inform. Technology and Innovation Found.

Fairhurst, C. (2017). Some challenges of deep mining. Engineering, 3(4), 527-537.

Fan, T., \& Chen, Y. (2010, September). A scheme of data management in the Internet of Things. In 2010 2nd IEEE InternationalConference on Network Infrastructure and Digital Content (pp. 110-114). IEEE.

Fensel, A., Tomic, D. K., \& Koller, A. (2017). Contributing to appliances' energy efficiency with Internet of Things, smart data and user engagement. Future Generation Computer Systems, 76, 329-338.

Forooshani, A. E., Bashir, S., Michelson, D. G., \& Noghanian, S. (2013). A survey of wireless communications and propagation modeling in underground mines. IEEE Communications surveys \& tutorials, 15(4), 1524-1545.

Frustaci, M., Pace, P., Aloi, G., \& Fortino, G. (2017). Evaluating critical security issues of the IoT world: Present and future challenges. IEEE Internet of things journal, 5(4), 2483-2495.

Futurist, C., The. (2001). "How the Internet Is Changing Our Lives.

Ghasemi, E., Amini, H., Ataei, M., \& Khalokakaei, R. (2014). Application of artificial intelligence techniques for predicting the flyrock distance caused by blasting operation. Arabian Journal of Geosciences, 7(1), 193-202.

Ghaychi Afrouz, S. (2020). Seismic Wave Velocity Variations in Deep Hard Rock Underground Mines by Passive Seismic Tomography (Doctoral dissertation, Virginia Tech).

Ghaychi Afrouz, S., \& Westman, E. C. (2018, October). Review and simulation of passive seismic tomography in block cave mining. In Proceedings of the Fourth International Symposium on Block and Sublevel Caving (pp. 223-230). Australian Centre for Geomechanics.

Gillies, A. S., Wu, H. W., Tuffs, N., \& Sartor, T. (2004, May). Development of a real time airflow monitoring and control system. In Proceedings Tenth US/Northern American Mine Ventilation Symposium (pp. 145-156).

Greer, C., Burns, M., Wollman, D., \& Griffor, E. (2019). Cyber-physical systems and internet of things. NIST Special Publication, 202(2019), 52.

Harbers, M., Bargh, M., Pool, R., Van Berkel, J., Van den Braak, S., \& Choenni, S. (2018, January). A conceptual framework for addressing IoT threats: challenges in meeting challenges. In Proceedings of the 51st Hawaii International Conference on System Sciences. 
Hiromoto, R. E., Haney, M., \& Vakanski, A. (2017, September). A secure architecture for IoT with supply chain risk management. In 2017 9th IEEE International Conference on Intelligent Data Acquisition and Advanced Computing Systems: Technology and Applications (IDAACS) (Vol. 1, pp. 431-435). IEEE.

Hongjiang, H., \& Shuangyou, W. (2008, August). The application of ARM and ZigBee technology wireless networks in monitoring mine safety system. In 2008 ISECS International Colloquium on Computing, Communication, Control and Management (Vol. 2, pp. 430-433). IEEE.

Horberry, T., Burgess-Limerick, R., \& Steiner, L. J. (2016). Human factors for the design, operation and maintenance of mining equipment. CRC Press.

Hu, S., Tang, C., Yu, R., Liu, F., \& Wang, X. (2013, November). Intelligent coal mine monitoring system based on the Internet of Things. In 2013 3rd International Conference on Consumer Electronics, Communications and Networks (pp. 380-384). IEEE.

Humphreys, D. (2001). Sustainable development: can the mining industry afford it?. Resources policy, 27(1), 1-7.

Hyder, Z., Siau, K., \& Nah, F. (2019). Artificial Intelligence, Machine Learning and Autonomous Technologies in Mining Industry. Journal of Database Management (JDM), 30(2), 67-79.

I-SCOOP. (2017). Industry 4.0: the fourth industrial revolution-guide to industrie 4.0.

Jaykumar, J., \& Blessy, A. (2014). Secure smart environment using IOT based on RFID. International Journal of Computer Science and Information Technologies, 5(2), 2493-2496.

Jo, B., \& Khan, R. M. A. (2018). An internet of things system for underground mine air quality pollutant prediction based on azure machine learning. Sensors, 18(4), 930.

Kaber, D. B., \& Riley, J. M. (1999). Adaptive automation of a dynamic control task based on secondary task workload measurement. International journal of cognitive ergonomics, 3(3), 169-187.

Kaber, D. B., Riley, J. M., Tan, K. W., \& Endsley, M. R. (2001). On the design of adaptive automation for complex systems. International Journal of Cognitive Ergonomics, 5(1), 37-57.

Kaplan, E., \& Hegarty, C. (2005). Understanding GPS: principles and applications. Artech house.

Khan, M. A., \& Salah, K. (2018). IoT security: Review, blockchain solutions and open challenges. Future Generation Computer Systems, 82, 395-411.

Khan, R., Khan, S. U., Zaheer, R., \& Khan, S. (2012, December). Future internet: the internet of things architecture, possible applications and key challenges. In 2012 10th international conference on frontiers of information technology (pp. 257-260). IEEE.
Khomenko, O., Rudakov, D., \& Kononenko, M. (2011). Automation of drill and blast design. Technical And Geoinformational Systems In Mining, 271-275.

Kibira, D., Kibira, D., Kumaraguru, S., \& Morris, K. C. (2016). Methods and tools for performance assurance of smart manufacturing systems. US Department of Commerce, National Institute of Standards and Technology.

Knight, M. (2018). Data Management and the Internet of Things.

Kumar, N. M., \& Mallick, P. K. (2018). The Internet of Things: Insights into the building blocks, component interactions and architecture layers. Procedia computer science, 132, 109-117.

Kunkun, P., \& Xiangong, L. (2014, October). Reliability evaluation of coal mine internet of things. In 2014 International Conference on Identification, Information and Knowledge in the Internet of Things (pp. 301-302). IEEE.

Lebedev, M. (2016). Automated systems as a part of geotechnical monitoring in construction and operation of transport tunnels. Procedia Engineering, 165, 448-454.

Liu, X., \& Liu, L. (2014). Design of Coal Mine Monitoring System Based on Internet of Things. In Bio-Inspired Computing-Theories and Applications (pp. 289-294). Springer, Berlin, Heidelberg.

Liu, Z., Li, C., Ding, Q., \& Wu, D. (2010, July). A coal mine personnel global positioning system based on wireless sensor networks. In 2010 8th World Congress on Intelligent Control and Automation (pp. 7026-7031). IEEE.

Liu, Z., Zhang, A., \& Li, S. (2013, July). Vehicle antitheft tracking system based on Internet of things. In Proceedings of 2013 IEEE International Conference on Vehicular Electronics and Safety (pp. 48-52). IEEE.

Lynas, D., \& Horberry, T. (2011). Human factor issues with automated mining equipment. The Ergonomics Open Journal, 4(1)

Lyu, Z., Chai, J., Xu, Z., Qin, Y., \& Cao, J. (2019). A comprehensive review on reasons for tailings dam failures based on case history. Advances in Civil Engineering, 2019.

Mahdavinejad, M. S., Rezvan, M., Barekatain, M., Adibi, P., Barnaghi, P., \& Sheth, A. P. (2018). Machine learning for Internet of Things data analysis: A survey. Digital Communications and Networks, 4(3), 161-175.

Mahmoodpour, Z., Molaei, F., \& Siavoshi, H. (2018, September). A Comparison of SED, Special Functions and Euler Deconvolution to Identify Magnetic Lineaments in Khuzestan Plain. In 2nd Conference on Geophysics for Mineral Exploration and Mining (Vol. 2018, No. 1, pp. 1-5). European Association of Geoscientists \& Engineers. 
Malik, V., \& Singh, S. (2019). Security risk management in IoT environment. Journal of Discrete Mathematical Sciences and Cryptography, 22(4), 697-709.

Markkanen, A. (2015). IoT Analytics Today and in 2020. Competitive Edge from Edge Intelligence. ABI Research, Oyster Bay, NY.

McGaughey, J. (2020). Artificial intelligence and big data analytics in mining geomechanics. Journal of the Southern African Institute of Mining and Metallurgy, 120(1), 15-21.

McNinch, M., Parks, D., Jacksha, R., \& Miller, A. (2019). Leveraging IIoT to Improve Machine Safety in the Mining Industry. Mining, Metallurgy \& Exploration, 36(4), 675-681.

Mijić, D., \& Varga, E. (2018, August). Unified iot platform architecture platforms as major iot building blocks. In 2018 International Conference on Computing and Network Communications (CoCoNet) (pp. 6-13). IEEE.

Mining Technology. 2019. "How the Internet of Things Is Transforming Australian Mining." 2019. https://www.mining-technology.com/processinstrumentation/how-the-internet-of-things-istransforming-australian-mining.

Moignard, R. (2008). Harnessing Mining Data to Improve Mine Performance.

Moridi, M. A., Kawamura, Y., Sharifzadeh, M., Chanda, E. K., \& Jang, H. (2014). An investigation of underground monitoring and communication system based on radio waves attenuation using ZigBee. Tunnelling and Underground Space Technology, 43, 362-369.

Muduli, L., Mishra, D. P., \& Jana, P. K. (2018). Application of wireless sensor network for environmental monitoring in underground coal mines: A systematic review. Journal of Network and Computer Applications, 106, 48-67.

Murphy, J. N., \& Parkinson, H. E. (1978). Underground mine communications. Proceedings of the IEEE, 66(1), 26-50.

Naik, S., \& Maral, V. (2017, May). Cyber security-IoT. In 2017 2nd IEEE International Conference on Recent Trends in Electronics, Information \& Communication Technology (RTEICT) (pp. 764-767). IEEE.

National Academies of Sciences, Engineering and Medicine. (2018). Monitoring and sampling approaches to assess underground coal mine dust exposures. National Academies Press.

National Research Council. (1992). Neem: a tree for solving global problems. The Minerva Group, Inc.

Nieto, A., \& Dagdelen, K. (2003). Development and testing of a vehicle collision avoidance system based on GPS and wireless networks for open-pit mines. Application of Computers and Operations Research in the Minerals Industries.
Nižetić, S., Djilali, N., Papadopoulos, A., \& Rodrigues, J. J. (2019). Smart technologies for promotion of energy efficiency, utilization of sustainable resources and waste management. Journal of cleaner production, 231, 565-591.

Paavola, M., \& Seppälä, P. (2016). Wireless networks in underground mines. In Industrial Wireless Sensor Networks (pp. 107-123). Woodhead Publishing.

Pallavi, S., \& Sarangi, S. R. (2017). Internet of things: architectures protocols and applications. Journal of Electrical and Computer Engineering, 2017, 1-0147.

Parasher, Y., Singh, P., \& Kaur, G. (2019). Green Smart Security System. Green and Smart Technologies for Smart Cities, 165-184.

Patel, P., Ali, M. I., \& Sheth, A. (2017). On using the intelligent edge for IoT analytics. IEEE Intelligent Systems, 32(5), 64-69.

Peik, B. (2020). A New Three-Dimensional Rockfall Trajectory Simulator for Open-Pit Mines (Doctoral dissertation).

Qian, Z. M., Yuan, Y. B., Zhang, S. S., \& Ren, G. F. (2016). Design of Online Mine Safety Detection System Based on Internet of Things. International Journal of Online and Biomedical Engineering (iJOE), 12(12), 60-62.

Qin, X., Fu, M., \& Shen, B. (2011, August). Coal mine gas wireless monitoring system based on WSNs. In 2011 Second International Conference on Digital Manufacturing \& Automation (pp. 309-312). IEEE.

Qiuping, W., Shunbing, Z., \& Chunquan, D. (2011). Study on key technologies of Internet of Things perceiving mine. Procedia Engineering, 26, 2326-2333.

Radanliev, P., De Roure, D. C., Maple, C., Nurse, J. R., Nicolescu, R., \& Ani, U. (2019). Cyber Risk in IoT Systems.

Rahimi, E., Asgari, G., Shekarian, Y., \& Nakini, A. (2019). Investigations of Natural Bitumen mineralization in Gilan-e-Gharb exploration block, Iran. The International Journal of Engineering and Science (IJES), 8(5), 55-68.

Rahimi, E., Maghsoudi, A., \& Hezarkhani, A. (2016). Geochemical investigation and statistical analysis on rare earth elements in Lakehsiyah deposit, Bafq district. Journal of African Earth Sciences, 124, 139-150.

Rahimi, E., Shekarian, Y., Farahani, S., Asgari, G., \& Nakini, A. (2020). New Approach in Application of the AHP-Fuzzy TOPSIS Method in Mineral Potential Mapping of the Natural Bitumen (Gilsonite): A Case Study from the Gilan-e-Gharb Block, the Kermanshah, West of Iran. American Journal of Engineering and Applied Sciences, 13(1), 96-110. 
Russell, S., \& Norvig, P. (2002). Artificial intelligence: a modern approach.

Sabins, F. F. (1999). Remote sensing for mineral exploration. Ore geology reviews, 14(3-4), 157-183.

Saroufim, C. E. (2016). Internet of Things and anomaly detection for the iron ore mining industry (Doctoral dissertation, Massachusetts Institute of Technology).

Satalich, J., \& Ricketson, R. (1998). Field test of Trimble 4000 real-time kinematic GPS survey system. Journal of surveying engineering, 124(1), 40-48.

Saxena, V., (2017). "Information Management for the Mining Industry.” Infosys. 2017. https://www.infosys.com/industries/minning/docum ents/plug-value-leakage.pdf

Shahmoradi, J., Mirzaeinia, A., Roghanchi, P., \& Hassanalian, M. (2020a). Monitoring of Inaccessible Areas in GPS-Denied Underground Mines using a Fully Autonomous Encased Safety Inspection Drone. In AIAA Scitech 2020 Forum (p. 1961)

Shahmoradi, J., Talebi, E., Roghanchi, P., \& Hassanalian, M. (2020b). A Comprehensive Review of Applications of Drone Technology in the Mining Industry. Drones, 4(3), 34.

Sharma, A., Gupta, S., \& Sharma, A. (2017a). IoT in Mining: A Review. International Journal of Electronics, Electrical and Computational System, 6(2), 84-91.

Sharma, V., Lim, J. D., Kim, J. N., \& You, I. (2017b). Saca: Self-aware communication architecture for iot using mobile fog servers. Mobile Information Systems, 2017.

Shekarian, Y., Hezarkhani, A., Anaraki, N. N., \& Hassani, A. N. (2017). Geochemistry and petrography of REE-bearing Fe-oxide assemblages in Choghart iron deposit, Yazd, Iran. Arabian Journal of Geosciences, 10(12), 273.

Sheridan \& Parasuraman, R. (2005). Human-automation interaction. Reviews of human factors and ergonomics, 1, 89-129.

Singh, A., Singh, U. K., \& Kumar, D. (2018, March). IoT in mining for sensing, monitoring and prediction of underground mines roof support. In 2018 4th International Conference on Recent Advances in Information Technology (RAIT) (pp. 1-5). IEEE.

Sittón-Candanedo, I., Alonso, R. S., García, Ó., Muñoz, L., \& Rodríguez-González, S. (2019). Edge computing, iot and social computing in smart energy scenarios. Sensors, 19(15), 3353.

Song, F., Zhu, M., Zhou, Y., You, I., \& Zhang, H. (2019). Smart collaborative tracking for ubiquitous power IoT in edge-cloud interplay domain. IEEE Internet of Things Journal.
Souri, A., Hussien, A., Hoseyninezhad, M., \& Norouzi, M. (2019). A systematic review of IoT communication strategies for an efficient smart environment. Transactions on Emerging Telecommunications Technologies, e3736.

Sun, E., Zhang, X., \& Li, Z. (2012). The internet of things (IOT) and cloud computing (CC) based tailings dam monitoring and pre-alarm system in mines. Safety science, 50(4), 811-815.

Thomas, M. O., \& Rad, B. B. (2018). Reliability evaluation metrics for internet of things, car tracking system: a review. Int. J. Inf. Technol. Comput. Sci.(IJITCS), 9(2), 1-10.

Tomar, P., Kaur, G., \& Singh, P. (2018). A prototype of IoT-based real time smart street parking system for smart cities. In Internet of Things and Big Data Analytics Toward Next-Generation Intelligence (pp. 243-263). Springer, Cham.

Vishwakarma, S. K., Upadhyaya, P., Kumari, B., \& Mishra, A. K. (2019, April). Smart energy efficient home automation system using IoT. In 2019 4th international conference on internet of things: Smart innovation and usages (IoT-SIU) (pp. 1-4). IEEE.

Visser, D. E. J., LeGoullon, M., Freedy, A., Freedy, E., Weltman, G., \& Parasuraman, R. (2008, September). Designing an adaptive automation system for human supervision of unmanned vehicles: A bridge from theory to practice. In Proceedings of the human factors and ergonomics society annual meeting (Vol. 52, No. 4, pp. 221225). Sage CA: Los Angeles, CA: SAGE Publications.

Wang, Q. F., Zhang, S., Yang, Y., \& Tang, L. (2009, December). The application of wireless sensor networks in coal mine. In 2009 7th International Conference on Information, Communications and Signal Processing (ICICS) (pp. 1-4). IEEE.

Watt, A., \& Eng, N. (2018). Database design.

Woo, M. W., Lee, J., \& Park, K. (2018). A reliable IoT system for personal healthcare devices. Future Generation Computer Systems, 78, 626-640.

Wortmann, F., \& Flüchter, K. (2015). Bus Inf Syst Eng (2015) 57: 221. Internet of Things Technology and Value Added.

Xia, X., Chen, Z., \& Wei, W. (2018). Research on monitoring and prewarning system of accident in the coal mine based on big data. Scientific Programming, 2018.

$\mathrm{Xu}, \mathrm{D}$. L., He, W., \& Li, S. (2014). Internet of things in industries: A survey. IEEE Transactions on industrial informatics, 10(4), 2233-2243. 
Yagimli, M., \& Varol, H. S. (2009, June). Mine detecting GPS-based unmanned ground vehicle. In 2009 4th International Conference on Recent Advances in Space Technologies (pp. 303-306). IEEE.

Yang, H., Kumara, S., Bukkapatnam, S. T., \& Tsung, F. (2019). The internet of things for smart manufacturing: A review. IISE Transactions, 51(11), 1190-1216.

Yinghua, Z., Guanghua, F., Zhigang, Z., Zhian, H., Hongchen, L., \& Jixing, Y. (2012). Discussion on application of IOT technology in coal mine safety supervision. Procedia engineering, 43, 233-237.
Zhang, Z. K., Cho, M. C. Y., Wang, C. W., Hsu, C. W., Chen, C. K., \& Shieh, S. (2014, November). IoT security: ongoing challenges and research opportunities. In 2014 IEEE 7th international conference on service-oriented computing and applications (pp. 230-234). IEEE.

Zhou, C., Damiano, N., Whisner, B., \& Reyes, M. (2017). Industrial Internet of Things: (IIoT) applications in underground coal mines. Mining engineering, 69(12), 50 . 